\title{
PENYULUHAN MALARIA DAN DENGUE, PELATIHAN KADER \\ PEMANTAU JENTIK NYAMUK SERTA PEMERIKSAAN KADAR HEMOGLOBIN PADA SISWA SEKOLAH DASAR DI SORONG, PAPUA BARAT
}

\section{(GIVING INFORMATION ABOUT MALARIA AND DENGUE, TRAINING OF MOSQUITO LARVAE MONITORING, AND EXAMINATION OF HB LEVELS IN ELEMENTARY SCHOOL STUDENTS IN SORONG, WEST PAPUA)}

\author{
Juniastuti ${ }^{1,2}$, Lynda Rossyanti ${ }^{1,3}$ \\ ${ }^{1}$ Program Magister Ilmu Kedokteran Tropis, ${ }^{2}$ Departemen Mikrobiologi, \\ ${ }^{3}$ Departemen Parasitologi, Fakultas Kedokteran Universitas Airlangga \\ e-mail: juniastutisyafik@yahoo.com
}

\begin{abstract}
Sorong Regency in West Papua Province, is an endemic area of malaria and dengue. The aims of this community service were 1) To increase the knowledge level of children about malaria and dengue, 2) To increase the skill of children in monitoring Aedes mosquito larvae, 3) To identify the proportion of anemia in children. The methods included 1) giving information about malaria and dengue, 2) cadre training of Aedes mosquito larvae monitoring, 3) $\mathrm{Hb}$ level examination. The targets were students in Elementary School Inpres 24 and Public Elementary School 22, in Sorong. The results showed no difference $(p>0.05)$ of knowledge level between before and after giving information. During 4 weeks of monitoring mosquito larvae, the mean percentage of students' house of Elementary School Inpres 24 and Public Elementary School 22 with positive mosquito larvae were $57 \%$ and $60.3 \%$, respectively. Most $(60 \%)$ of students suffered from anemia in Public Elementary School 22, while only 38\% of those in Elementary School Inpres 24. Conclusion: Giving information was not able to increase knowledge level on malaria and dengue in elementary school students in Sorong. They had a good capability to monitor mosquito larvae. The proportion of anemia in elementary school students in Sorong was $38-60 \%$.
\end{abstract}

Keywords: Aedes mosquito, anemia, dengue, larvae observer student, malaria,

\begin{abstract}
abstrak
Kabupaten Sorong, Papua Barat, merupakan daerah endemis malaria dan dengue. Tujuan kegiatan pengabdian masyarakat ini adalah 1) Meningkatkan pengetahuan anak tentang malaria dan dengue, 2) Meningkatkan ketrampilan anak dalam memantau jentik nyamuk Aedes serta 3) Mengidentifikasi proporsi anemia pada anak. Metode kegiatan pengabdian masyarakat meliputi: 1) Penyuluhan tentang malaria dan dengue, 2) Pelatihan kader pemantau jentik nyamuk Aedes, 3) Pemeriksaan kadar $\mathrm{Hb}$, untuk mendeteksi anemia. Sasaran kegiatan adalah siswa di SD Inpres 24 dan SD Negeri 22, kabupaten Sorong. Hasil evaluasi menunjukkan tidak ada beda ( $p>0.05)$ tingkat pengetahuan antara sebelum dan setelah penyuluhan. Selama 4 minggu pemantauan, rerata persentase rumah siswa SD Inpres 24 dengan jentik nyamuk positif sebesar 57.9\%; sedangkan rerata persentase rumah siswa SD Negeri 22 dengan jentik nyamuk positif sebesar $60.3 \%$. Sebagian besar (60\%) siswa di SD Negeri 22 menderita anemia, sedangkan di SD Inpres 24 sebanyak 38\% siswa menderita anemia. Kesimpulan:
\end{abstract}


Penyuluhan belum dapat meningkatkan pengetahuan tentang malaria dan dengue pada siswa SD di Sorong. Siswa mampu melakukan pemantauan jentik nyamuk. Proporsi anemia pada siswa SD di Sorong sebesar 38-60\%.

Kata kunci: anemia, dengue, malaria, nyamuk Aedes, siswa pemantau jentik

\section{PENDAHULUAN}

Sebanyak 3.2 milyar atau separuh penduduk dunia diperkirakan berisiko terjangkit malaria. Pada tahun 2016, dijumpai sebanyak 216 juta kasus malaria di seluruh dunia, dengan angka kematian sebanyak 445,000. Angka kematian akibat malaria pada anak usia di bawah lima tahun mengalami penurunan dari 440,000 pada tahun 2010 menjadi 285,000 pada tahun 2016 (WHO, 2017). Walaupun tejadi penurunan angka kematian akibat malaria, tetapi malaria masih merupakan penyebab kematian utama pada anak (Elyazar dkk., 2011).

Berdasar tingkat stratifikasi API (Annual Parasite Incidence), Indonesia bagian timur termasuk dalam stratifikasi malaria tinggi. Data Ditjen PP dan PL Kemenkes RI pada tahun 2014 menunjukkan bahwa Papua memiliki nilai API tertinggi sebesar 29.57 (Ditjen PP\&PL Kemenkes RI, 2014). Tingginya kasus tersebut antara lain disebabkan pembangunan yang tidak berwawasan lingkungan, mobilitas penduduk dari dan ke daerah endemis malaria, serta resistensi obat malaria. Masalah malaria menjadi semakin sulit diatasi. karena kejadian kesakitan dapat berlangsung berulang kali. Masih tingginya angka kejadian relaps malaria di Indonesia dipengaruhi oleh a.l. tingkat pendidikan yang masih rendah serta sikap pencegahandan pencarian pengobatan yang kurang baik pada saat menderita malaria (Zega, 2006).

Papua Barat merupakan provinsi dengan prevalensi malaria yang masih tinggi. Berdasar laporan selama tahun 2015, sebanyak 23,548 kasus malaria terkonfirmasi melalui uji laboratorium. Jika diasumsikan 1 kasus hanya terjadi pada 1 orang selama 1 tahun, maka sebesar 2.7 persen penduduk Papua Barat pernah terjangkit malaria. Berdasarkan data Dinas Kesehatan Kota Sorong pada tahun 2012 menunjukkan bahwa kasus malaria pada penderita dengan pemeriksaan sediaan darah didapatkan 14,310 kasus dengan API sebesar 49.8 per 1,000 penduduk, sedangkan pada tahun 2014 terjadi penurunan menjadi 7,617 kasus (Dinkes Sorong, 2015).

Komplikasi yang dapat terjadi pada bayi dan balita yang sering menderita malaria adalah anemia, yang berdampak terjadinya malnutrisi dan gangguan pertumbuhan. Bersamaan dengan tingginya angka kesakitan malaria, hasil studi di wilayah Sorong Selatan pada tahun 2015 menunjukkan angka kejadian anemia pada anak cukup tinggi, 30 anak anemia dengan $\mathrm{Hb}<10 \mathrm{~g} / \mathrm{dl}, 35$ anak dengan MCV $<80$ fl dan 34 anak dengan $\mathrm{MCH}<28 \mathrm{~g} / \mathrm{dl}$ (Abdussalam dkk., 2016). Anemia selain merupakan komplikasi dari malaria, juga meningkatkan resiko kematian akibat malaria pada anak. Anemia jangka panjang yang tidak tertangani dengan baik dapat menimbulkan kematian.

Berbagai upaya telah dilakukan untuk menurunkan angka kesakitan dan kematian karena malaria, namun upaya tersebut belum dapat diimplementasikan secara maksimal, karena belum semua keluarga dan masyarakat dilibatkan. Untuk mengantisipasi hal 
tersebut, muncul gagasan Keluarga Bebas (Kebas) Malaria sebagai upaya untuk pencegahan dan pengobatan malaria pada ibu hamil, bayi, dan balita. Kebas Malaria dilaksanakan dengan pendekatan keluarga oleh kader kesehatan di tingkat Posyandu, dengan melakukan kunjungan rumah ke rumah. Tujuan Kebas malaria ini adalah untuk mewujudkan tiga bebas di dalam keluarga, yaitu : pertama, bebas dari kekurangan informasi terhadap malaria; dua, bebas dari penggunaan kelambu berinsektida yang tidak tepat; dan tiga, bebas dari ketidakpatuhan minum obat anti malaria bagi penderita (Media Papua, 2016). Seiring dengan program kementerian kesehatan RI yang berupaya untuk mewujudkan bebas malaria pada tahun 2030, maka upaya yang dapat dilakukan a.1. penyuluhan tentang malaria secara luas dan deteksi dini di daerah endemis.

Kasus demam berdarah dengue (DBD) juga merupakan masalah kesehatan yang penting di Sorong, Papua Barat. Terdapat lima daerah endemis dengue di provinsi Papua Barat, yaitu kota Sorong, Manokwari, kabupaten Sorong, Fakfak dan Kaimana. Faktor yang mempengaruhi tingginya insiden DBD di Papua Barat adalah faktor lingkungan dan mobilisasi penduduk (Dinkes Papua, 2017). Pusat Data dan Surveilens Epidemiologi Kemenkes RI (2010) melaporkan adanya pergeseran kelompok usia dengan jumlah kasus DBD terbesar yaitu dari usia $<15$ tahun menjadi $\square 15$ tahun, serta faktor curah hujan tinggi dan keberadaan lingkungan biologis yang mendukung perkembangbiakan nyamuk berpotensi mempengaruhi tingginya kejadian DBD.Pencegahan penyakit DBD yang selama ini digalakkan Pemerintah adalah Gerakan 3M/Gerakan 3M Plus (Pusat Data dan Surveilens Epidemiologi Kemenkes RI, 2010). Namun ternyata penyakit DBD masih selalu terjadi tiap tahun (terutama saat musim hujan), karena masyarakat sering tidak peduli dan tidak menjalankan gerakan $3 \mathrm{M}$ Plus secara teratur dan berkesinambungan. Masyarakat tidak menyadari bahwa di dalam/luar rumahnya terpelihara nyamuk Aedes sp. (Aedes aegypti dan Aedes albopictus) yang merupakan vektor/penular penyakit DBD.

Tujuan kegiatan pengabdian masyarakat ini adalah :Meningkatkan pengetahuan siswa SD di Sorong tentang malaria dan dengue.Meningkatkan ketrampilan siswa SD dalam memantau jentik nyamuk di Sorong. Mengidentifikasi proporsi anemia pada siswa SD di Sorong

\section{METODE PENGABDIAN MASYARAKAT}

Untuk menangani suatu masalah kesehatan di suatu daerah endemis, penting diperhatikan ketiga item vital, yaitu host, agent, dan environment. Identifikasi faktor dari masing-masing item tersebut yang berkontribusi dalam kejadian masalah kesehatan perlu ditindaklanjuti dengan melakukan tindakan solusi yang sesuai. Tindakan solusi terebut meliputi pencegahan primer, pencegahan sekunder dan pencegahan tersier (Gambar 1). Dengan kegiatan penyuluhan kesehatan tentang malaria dan dengue serta pelatihan memantau jentik (pencegahan primer) ini, diharapkan dapa meningkatkan pengetahuan - memperbaiki sikap - memperbaiki perilaku host (siswa SD), dalam mencegah penularan infeksi Dengue. Secara tidak langsung, pengetahuan yang diberikan kepada anak dapat disebarkan ke lingkungan sosial mereka (keluarga, tetangga, teman, dll). Selain itu, dengan deteksi dini anemia (pencegahan sekunder), diharapkan mencegah dampak lanjut dari anemia a.l. dalam tumbuh kembang anak. Kegiatan pengabdian masyrakat ini diharapkan dapat berkontribusi dalam menurunkan angka kesakitan malaria dan DBD di Sorong. 


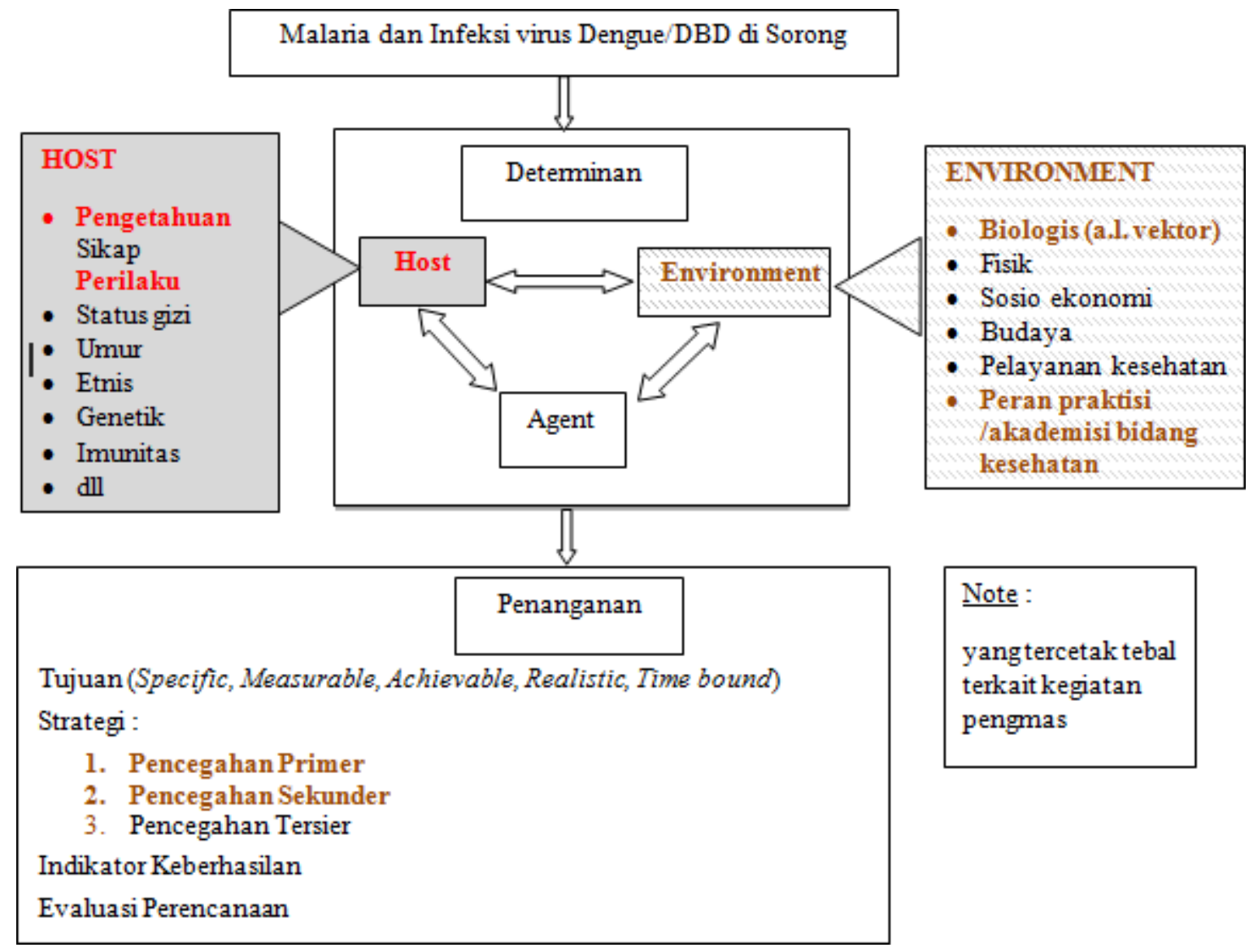

Gambar 1. Kerangka konsep pemecahan masalah

Program pengeabdian masyarakat yang akan ditawarkan dari kegiatan ini meliputi beberapa aktivitas yang melibatkan masyarakat, pemangku kepentingan di tingkat desa. Rangkaian aktivitas program pengabian masyarakat dilakukan meliputi:

\section{Bentuk dan Sasaran Aktivitas}

Kegiatan pengabdian masyarakat akan diberikan dalam 3 bentuk : Penyuluhan tentang malaria dan dengue, Pelatihan kader pemantau jentik nyamuk Aedes (vektor Dengue), Pemeriksaan kadar Hb, untuk mendeteksi anemia. Sasaran kegiatan ini adalah siswasiswi di 2 SD di kabupaten Sorong.

\section{Kegiatan Penyuluhan dan Pelatihan.}

Dilakukan pre test sebelum penyuluhan. Penyuluh memberikan materi tentang malaria dan dengue (meliputi gambaran penyakit, penyebab, gejala, pengobatan secara umum dan upaya pencegahan) dengan alat bantu presentasi (LCD/laptop/alat lain yang disediakan pihak sekolah) selama 1 jam. Pelatihan memantau jentik nyamuk Aedes dengan alat bantu presentasi selama 1 jam. Selanjutnya diberikan kesempatan untuk tanya jawab selama 1 jam. Dilakukan post test setelah penyuluhan. Pembagian buku saku. 


\section{Kegiatan pemeriksaan kadar Hb}

Persiapan : pendaftaran siswa yang akan diukur kadar Hb nya. Diharapkan sebanyak 100 siswa untuk 2 SD (@50 siswa tiap SD) bersedia diperiksa kadar Hb nya. Pemeriksaan kadar $\mathrm{Hb}$ memakai handschoen. Melakukan tindakan antiseptik pada kulit jari tangan yang akan diambil darahnya, menggunakan usap alkohol 70\%. Menusuk ujung jari tangan dengan menggunakan lancet. Darah yang keluar ditempelkan pada strip yang telah terpasang pada alat $\mathrm{Hb}$ meter, ditunggu beberapa detik, dan alat akan menunjukkan angka kadar Hb. Jarum bekas ditutup dan dibuang secara aman

\section{Pencatatan dan pelaporan kadar $\mathbf{H b}$}

Nilai pre test dan post test dikumpulkan untuk dianalisis, sebagai indikator keberhasilan kegiatan penyuluhan. Dari sejumlah pertanyaan pada kuesioner, dinyatakan : Baik, jika persentase jawaban benar sebanyak 70\%-100\%, Cukup, jika persentase jawaban benar sebanyak 40\%-69\%, Kurang, jika persentase jawaban benar sebanyak 0-39\%

\section{Analisis statistik dilakukan dengan Paired Sample t-Test.}

Tingkat ketrampilan siswa dalam memantau jentik nyamuk Aedes yang diukur dari kartu pemantauan jentik nyamuk. Kartu tersebut diisi dengan keberadaan jentik nyamuk di rumah tiap siswa setiap minggu selama 1 bulan. Data yang diperoleh dianalisis secara deskriptif. Tingkat anemia diklasifikasikan berdasar kadar $\mathrm{Hb}$ (Tabel 1) dan dianalisis secara deskriptif.

Tabel 1. Klasifikasi Anemia (WHO, 2014)

\begin{tabular}{lcccc}
\hline Umur & Non & \multicolumn{3}{c}{ Tingkat anemia } \\
(tahun) & Anemia & Ringan & Sedang & Berat \\
\hline $5-11$ & $\square 115$ & $110-114$ & $80-109$ & $<80$ \\
$12-14$ & $\square 119$ & $110-119$ & $80-109$ & $<80$ \\
\hline
\end{tabular}

(Keterangan : Hb dalam $\mathrm{g} / \mathrm{l}$, skala data : interval)

\section{Lokasi, waktu dan durasi kegiatan}

Kegiatan pengabdian masyarakat (penyuluhan, pelatihan, pemeriksaan kadar $\mathrm{Hb}$ ) ini dilaksanakan pada bulan Agustus 2017 di dua SD di Sorong selama 3-4 hari, dan pemantauan monitoring jentik nyamuk oleh siswa SD selama 1 bulan setelah pelatihan.

\section{HASIL DAN PEMBAHASAN}

Kegiatan pengabdian masyarakat dilakukan di 2 SD di dalam wilayah kerja Puskesmas Mayamuk, Kabupaten Sorong, Provinsi Papua Barat. Kabupaten Sorong merupakan salah satu daerah yang terletak di kepala burung Pulau Papua. Kabupaten Sorong memiliki iklim tropis yang lembab dan panas, dikelilingi oleh kabupaten Raja Ampat (sebelah utara dan barat), kabupaten Sorong Selatan (sebelah selatan) dan kabupaten Manokwari (sebelah timur). Luas kabupaten Sorong 12,159.42 $\mathrm{km}^{2}$. Penghasilan utama penduduk kabupaten Sorong adalah berasal dari bidang pertanian, perkebunan, kehutanan, perburuan dan perikanan; diikuti bidang pertambangan (BPS Sorong, 2017).

Mayamuk merupakan salah satu dari 19 kecamatan/distrik yang secara administratif terdaftar di kabupaten Sorong, dengan luas kecamatan Mayamuk $217.22 \mathrm{~km}^{2}$. Wilayah kecamatan Mayamuk dibatasi oleh kelurahan Mariyai distrik Mariyat (sebelah utara), 
kelurahan Majaran distrik Salawati (sebelah selatan), kelurahan Klamono distrik Klamono (sebelah timur) - dan kabupaten Raja Ampat (sebelah barat). Kecamatan Mayamuk terdiri dari 6 kampung dan 2 kelurahan. Jumlah penduduk distrik Mayamuk pada tahun 2017 sebanyak 11,851 terdiri dari 6,203 laki-laki dan 5,648 perempuan (BPS Sorong, 2017). Di kecamatan Mayamuk, ada 1 Puskesmas dan 7 Puskesmas Pembantu. Ketersediaan sekolah meliputi 11 SD, 4 SMP dan 3 SMA. Puskemas Mayamuk melayani berbagai pemeriksaan, termasuk di antaranya adalah poli malaria. Beberapa program kegiatannya meliputi juga kesehatan lingkungan, antara lain pembinaan dan pemeriksaan rumah sehat dan survei jentik nyamuk, serta penyuluhan malaria dan Dengue. Data survei jentik nyamuk yang dilakukan pada bulan Januari 2017 di 4 RT di kelurahan Makbusun distrik Sorong menunjukkan jentik nyamuk positif berkisar 30$52 \%$ dengan rerata $41.8 \%$.

Kegiatan pengabdian masyarakat dilaksanakan pada tanggal 2-5 Agustus 2017 di 2 SD, yaitu SD Inpres 24 (di desa Makbusun) dan SD Negeri 22 (di desa Klain), di wilayah kerja Puskesmas Mayamuk, Kabupaten Sorong. Kegiatan tersebut berjalan lancar, dengan didampingi guru SD terkait dan beberapa petugas puskesmas Mayamuk yang sedang bertugas untuk melakukan pemeriksaan kesehatan rutin di SD tersebut didukung ketersediaan listrik dan perangkatnya di SD tersebut.

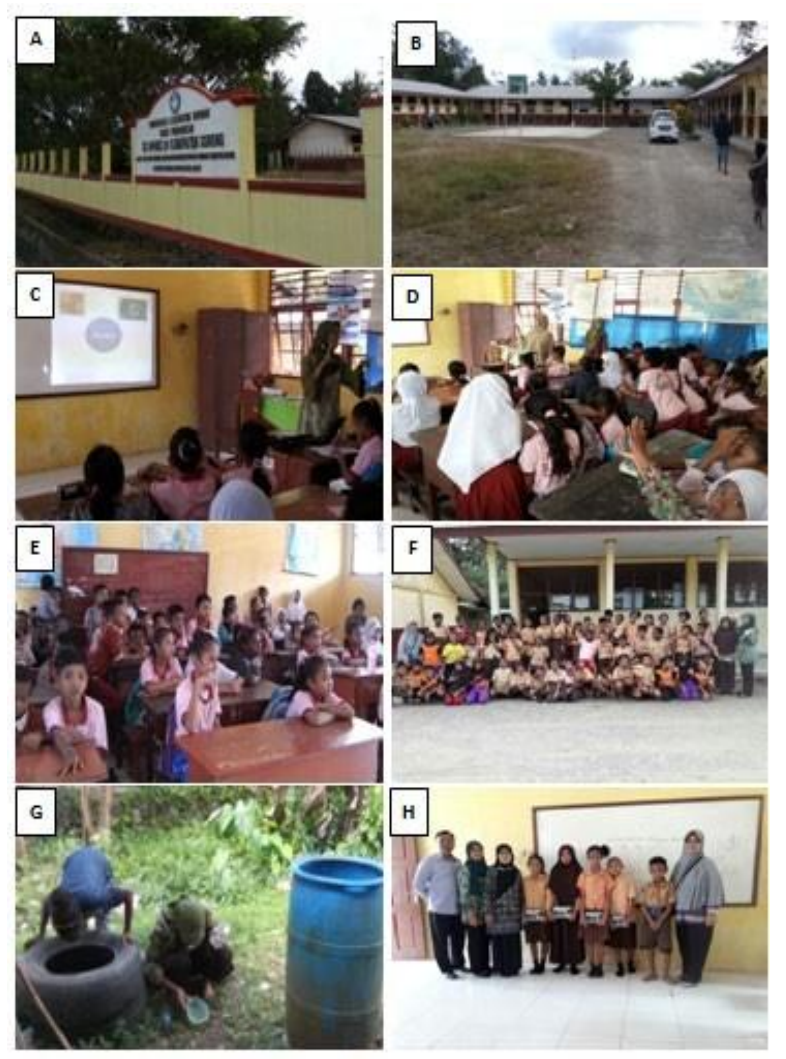

Gambar 2. Suasana di SD Inpres 24 Kabupaten Sorong

(Keterangan : A : Papan nama SD; B : Ruang kelas; C, D, E : Suasana penyuluhan dan pelatihan; F : Peserta penyuluhan dan pelatihan; G : Pemantauan jentik nyamuk di lingkungan rumah seorang siswa; $\mathrm{H}$ : Pemberian buku saku bagi siswa dengan nilai post test terbaik) 
Jumlah total siswa sekitar 200. Siswa di SD ini banyak yang berasal dari luar Papua (terutama Jawa), karena daerah di lingkungan SD ini adalah daerah transmigran. Guruguru banyak pula yang berasal dari Jawa. Perilaku kesehatan siswa secara umum tampak kurang baik. Beberapa siswa tampak tidak memakai sepatu, bahkan ada pula beberapa siswa yang menjinjing sepatunya agar tidak kotor. Penyuluhan kesehatan perlu dilakukan lebih aktif pada siswa di SD ini, agar tingkat pengetahuan tentang kesehatan meningkat sehingga perilaku untuk memelihara kesehatan lebih baik.

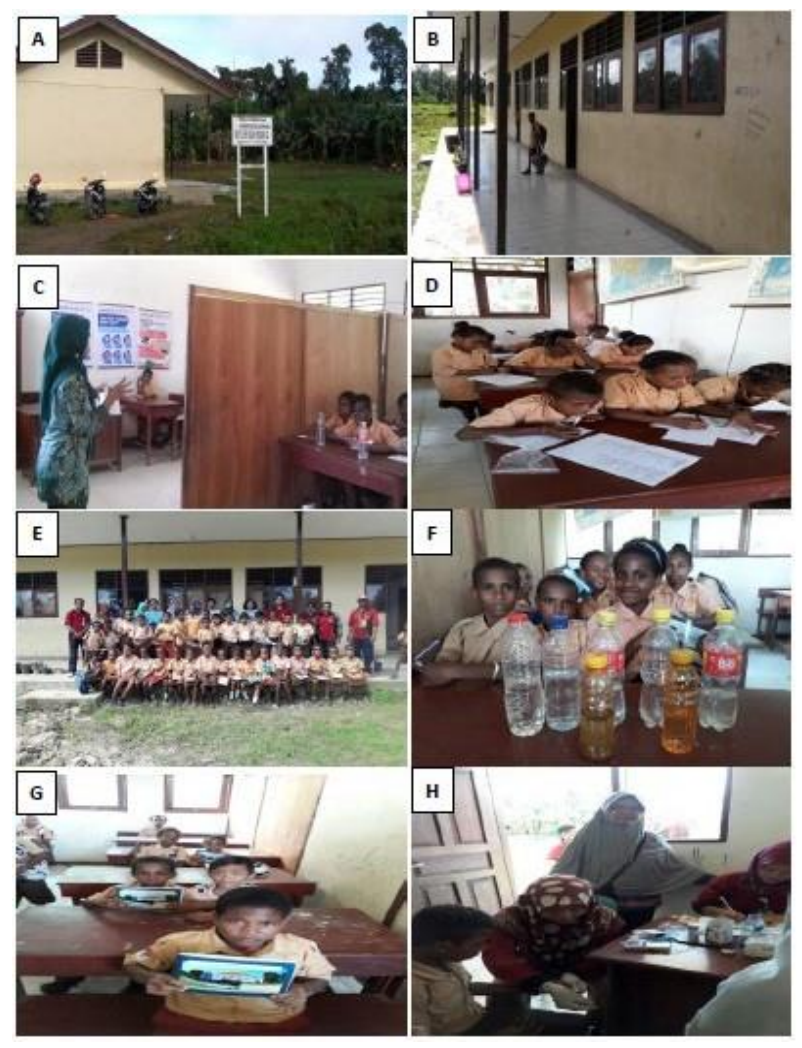

Gambar 3. Suasana di SD Negeri 22 Kabupaten Sorong

(Keterangan : A : Papan nama SD; B : Ruang kelas; C : Penyuluhan dan pelatihan; D ; Post test; E : Peserta penyuluhan dan pelatihan; F : Hasil pemantauan jentik nyamuk oleh siswa SD; $\mathrm{G}$ : Pemberian buku saku; $\mathrm{H}$ : Pemeriksaan kadar $\mathrm{Hb}$ )

Jumlah total siswa di SD Negeri 22 sekitar 100. Berbeda dengan SD Inpres 24, siswa di SD Negeri 22 ini banyak yang berasal dari Papua, namun guru banyak yang berasal dari Jawa juga. Perilaku kesehatan siswa secara umum tampak kurang baik. Kebanyakan siswa tidak memakai sepatu. Penyuluhan kesehatan juga perlu dilakukan lebih aktif pada siswa di SD ini, agar tingkat pengetahuan tentang kesehatan meningkat sehingga perilaku untuk memelihara kesehatan lebih baik.

Penyuluhan tentang malaria dan dengue serta pelatihan pemantauan jentik nyamuk dilakukan kepada 35 siswa dari kelas 4-6. Sebelum penyuluhan, dilakukan pre test yang berisi kuesioner tentang malaria, infeksi Dengue dan pemantauan jentik nyamuk Aedes pada 35 siswa. Kemudian setelah penyuluhan dan pelatihan, dilaksanakan post test dengan kuesioner yang sama. Namun ternyata yang mengikuti post test hanya 32 siswa. 
Kesan yang tampak, secara umum, respon dari siswa SD ini terhadap materi yang diberikan, kurang. Saat diberikan kuesioner, dan diminta menulis nama dan kelas, beberapa siswa mengalami kesulitan. Tampaknya kemampuan tulis menulis dan berbahasa Indonesia menjadi kendala dalam penerimaan materi. Saat diberikan pertanyaan secara lisan pun, respon siswa kurang. Di akhir pertemuan tersebut, diberikan sertifikat penyuluhan dan suvenir pada siswa tersebut. Koordinasi dengan pihak guru dilakukan terkait pengumpulan pemantauan jentik nyamuk oleh siswa setiap minggu, termasuk untuk pengiriman datanya ke Surabaya. Pemeriksaan kadar $\mathrm{Hb}$ dilakukan pada 65 siswa dari kelas 1-6 di ruang kelas berbeda. Pemeriksaan ini dilakukan untuk mengetahui proporsi anemia pada siswa SD tersebut yang tinggal di daerah endemis malaria.

Pada hari berikutnya (hari IV), dilakukan monitoring hasil tugas memantau jentik nyamuk Aedes yang diberikan pada saat pelatihan. Secara umum, siswa berhasil mengumpulkan jentik nyamuk dengan baik, walaupun ada sedikit siswa yang ternyata mengumpulkan jentik nyamuk Culex. Diberikan penekanan lagi kepada siswa di mana tempat yang terbaik untuk menemukan jentik nyamuk Aedes, serta apa upaya yang perlu dilakukan bila menemukan jentik nyamuk Aedes di lingkungan rumah mereka. Kondisi SD, kegiatan penyuluhan dan pelatihan serta hasil pemantauan jentik nyamuk ditampilkan pada Gambar 3.

\section{Evaluasi Penyuluhan}

\section{SD Inpres 24}

Sebanyak 64 siswa kelas 5 dan 6 mengikuti pre test dan post test. Nilai pretest berkisar 8.3 - 75, dengan rerata 37.3, sedangkan nilai post test berkisar 8.3 - 66.7, dengan rerata sedikit meningkat (menjadi 38.4). Setelah diklasifikasikan berdasar tingkat pengetahuan, hasil pre test kebanyakan siswa menunjukkan tingkat pengetahuan kurang (50\%), diikuti tingkat pengetahuan cukup (48.4\%) dan hanya 1 siswa dengan tingkat pengetahuan baik (1.6\%) (Gambar 4A). Sedangkan hasil post test menunjukkan dominasi yang sama seperti hasil pre test; terbanyak dengan tingkat pengetahuan kurang (56.2\%), diikuti dengan tingkat pengetahuan cukup (43.8\%), namun tidak ada siswa yang menunjukkan tingkat pengetahuan baik (Gambar 4B). Hasil analisis statistik menunjukkan tidak ada perbedaan tingkat pengetahuan yang bermakna antara sebelum (pre test) dan sesudah (post test) penyuluhan ( $\mathrm{p}=0.284 ; \mathrm{p}>0.05)$.
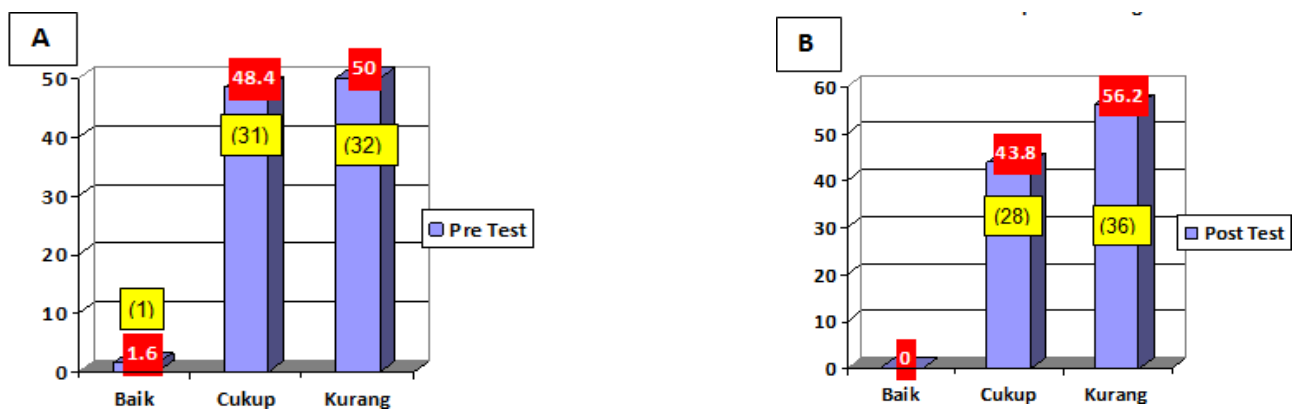

Gambar 4. Distribusi persentase tingkat pengetahuan siswa SD Inpres 24 dari hasil pre test (A) dan post test (B). (Keterangan : angka dalam kotak merah adalah angka dalam persentase, angka dalam kotak kuning adalah angka numerik) 


\section{SD Negeri 22}

Sebanyak 35 siswa kelas 4-6 mengikuti penyuluhan, namun hanya 32 siswa yang mengikuti pre test dan post test, 3 siswa lainnya hanya mengumpulkan jawaban pre test. Kisaran nilai post test dan pre test sama, antara 8.3 - 58.3, namun dengan rerata sedikit meningkat (pre test 28.1 dan post test 30.2). Hasil klasifikasi berdasar tingkat pengetahuan dari hasil pre test dan post test menunjukkan kebanyakan siswa $(75 \%)$ dengan tingkat pengetahuan kurang dan sisanya (25\%) dengan tingkat pengetahuan cukup (Gambar 5). Hasil analisis statistik menunjukkan tidak ada perbedaan tingkat pengetahuan antara sebelum (pre test) dan sesudah (post test) penyuluhan ( $\mathrm{p}=0.328$; $\mathrm{p}>0.05)$.
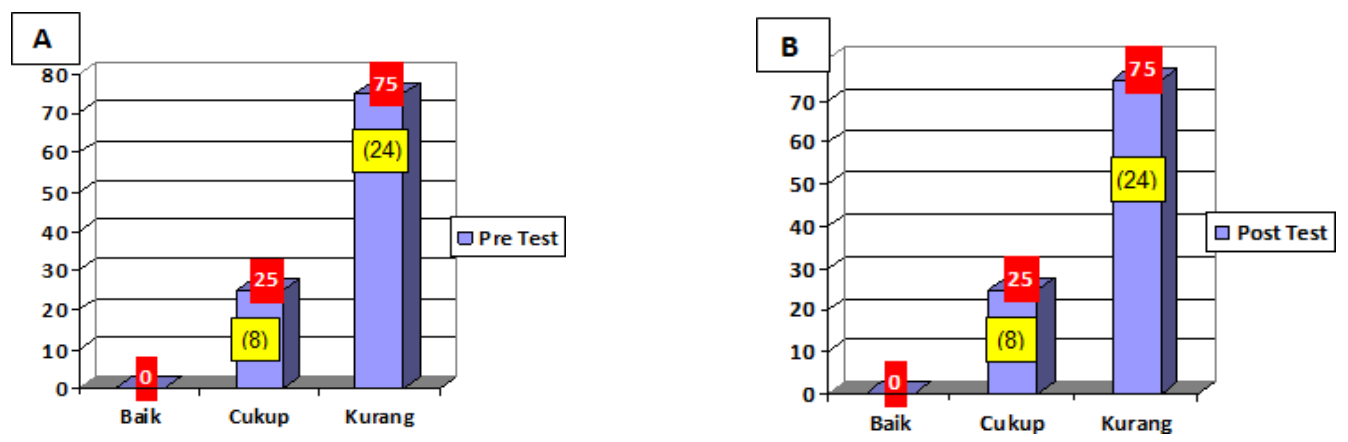

Gambar 5. Distribusi persentase tingkat pengetahuan siswa SD Negeri 22 dari hasil pre test (A) dan post test (B). (Keterangan : angka dalam kotak merah adalah angka persentase, angka dalam kotak kuning adalah angka numerik)

Hasil evaluasi pada siswa di kedua SD menunjukkan tidak ada beda antara sebelum dan setelah penyuluhan/ pelatihan, walaupun ada sedikit peningkatan rerata nilai post test dibanding dengan pre test. Kemampuan verbal secara umum dari siswa yang kurang, turut mempengaruhi. Kesiapan siswa dalam menerima asupan materi penyuluhan dari penyuluh baru patut dipertimbangkan. Mungkin diperlukan pengenalan dahulu untuk mengetahui bagaimana cara berinteraksi dengan siswa di kedua SD tersebut, agar mereka dapat menerima penyuluhan dengan lebih baik. Penyuluhan/pelatihan diberikan pada siswa SD kelas 4-6 dengan asumsi kemampuan dalam menyerap informasi sudah memadai. Secara umum, kemampuan siswa SD Inpres 24 lebih baik daripada siswa SD Negeri 22, terlihat dari rentang nilai pre test dan post test. Tampaknya penyuluhan/pelatihan perlu dilakukan berulang, agar tingkat pengetahuan mereka tentang malaria, infeksi Dengue dan pemantauan jentik nyamuk meningkat bermakna. Kemampuan pendidikan SD di luar Jawa, terutama di daerah pinggiran, sangat perlu ditingkatkan lebih baik lagi. Kemampuan dalam bidang pendidikan dari penduduk di suatu daerah sangat mempengaruhi profil bidang lain, termasuk bidang kesehatan (profil penyakit).

\section{Data Survei Jentik Nyamuk SD Inpres 24}

Dari 64 siswa yang mengikuti penyuluhan, hanya 19 (30\%) siswa yang mengumpulkan data survei jentik nyamuk selama 4 minggu (1x/minggu). Dukungan guru pendamping sangat diperlukan dalam pengumpulan data survei jentik nyamuk ini, namun tampaknya dukungan tersebut kurang optimal. Distribusi tempat-tempat perindukan nyamuk 
terangkum pada Tabel 2. Tiap siswa yang menemukan jentik nyamuk, hanya menuliskan 1 macam tempat perindukan saja. Dari 46 tempat perindukan yang dilaporkan, bak mandi merupakan tempat perindukan nyamuk terbanyak, diikuti drum, ember, kaleng bekas, ban bekas dan baskom serta pot bunga. Ada 2 siswa yang menemukan jentik nyamuk di 3 macam tempat, yaitu bak sampah, kolam dan got, yang sebenarnya bukanlah tempat perindukan nyamuk Aedes. Pada analisis berikutnya, penemuan jentik nyamuk pada tempat perindukan bukan jentik nyamuk Aedes, dihitung sebagai jentik nyamuk negatif. Dari 19 rumah siswa, hasil survei jentik nyamuk terangkum pada Gambar 6 dan Tabel 3. Selama 4 minggu pemantauan tersebut, persentase rumah siswa SD Inpres 24 dengan jentik nyamuk positif berkisar 21.1 $84.2 \%$ dengan rerata $57.9 \%$.

\section{SD Negeri 22}

Dari 35 siswa yang mengikuti penyuluhan, ada 34 (97\%) siswa yang mengumpulkan data survei jentik nyamuk selama 4 minggu (1x/minggu). Minat siswa SD Negeri 22 tampaknya lebih baik dalam melakukan pemantauan jentik nyamuk dibandingkan siswa SD Inpres 24. Respon guru pendamping saat koordinasi pengumpulan data pemantauan jentik nyamuk, juga tampak lebih baik.

Tabel 2. Urutan terbanyak tempat perindukan jentik nyamuk di lingkungan rumah siswa SD Inpres 24 selama minggu I s.d minggu IV

\begin{tabular}{lc}
\hline \multicolumn{1}{c}{ Tempat perindukan jentik nyamuk } & Jumlah (persentase) \\
\hline Bak mandi & $13(28.3)$ \\
Drum & $11(23.9)$ \\
Ember & $7(15.2)$ \\
Kaleng bekas & $5(10.9)$ \\
Ban bekas & $3(6.5)$ \\
Baskom & $3(6.5)$ \\
Pot bunga & $1(2.2)$ \\
Bak sampah* & $1(2.2)$ \\
Kolam* & $1(2.2)$ \\
Got* & $1(2.2)$ \\
\hline Total & $46(100)$ \\
\hline \multicolumn{2}{c}{ Keterangan : ${ }^{*}$ bukan tempat perindukan jentik nyamuk Aedes) }
\end{tabular}


Tabel 3. Keberadaan jentik nyamuk di lingkungan rumah siswa SD Inpres 24 selama minggu I s.d minggu IV

\begin{tabular}{|c|c|c|c|c|c|}
\hline \multicolumn{4}{|c|}{ Keberadaan jentik nyamuk } & \multirow{2}{*}{$\begin{array}{c}\text { Jumlah } \\
\text { (persentase) } \\
\text { rumah }\end{array}$} & \multirow{2}{*}{$\begin{array}{c}\text { Total } \\
\text { persentase } \\
\text { rumah } \\
\end{array}$} \\
\hline Minggu I & Minggu II & Minggu III & Minggu IV & & \\
\hline \multicolumn{6}{|c|}{ Tidak ada perubahan } \\
\hline+ & + & + & + & $4(21.1)$ & \multirow[t]{2}{*}{31.6} \\
\hline- & - & - & - & $2(10.5)$ & \\
\hline \multicolumn{6}{|c|}{ Menunjukkan penurunan jentik nyamuk positif } \\
\hline+ & - & - & - & $3(15.8)$ & \multirow[t]{2}{*}{31.6} \\
\hline+ & + & - & - & $3(15.8)$ & \\
\hline \multicolumn{6}{|c|}{ Jentik nyamuk ditemukan lagi } \\
\hline+ & + & - & + & $5(26.3)$ & \multirow{3}{*}{36.9} \\
\hline+ & - & - & + & $1(5.3)$ & \\
\hline- & + & - & + & $1(5.3)$ & \\
\hline Total & & & & $19(100)$ & 100 \\
\hline
\end{tabular}

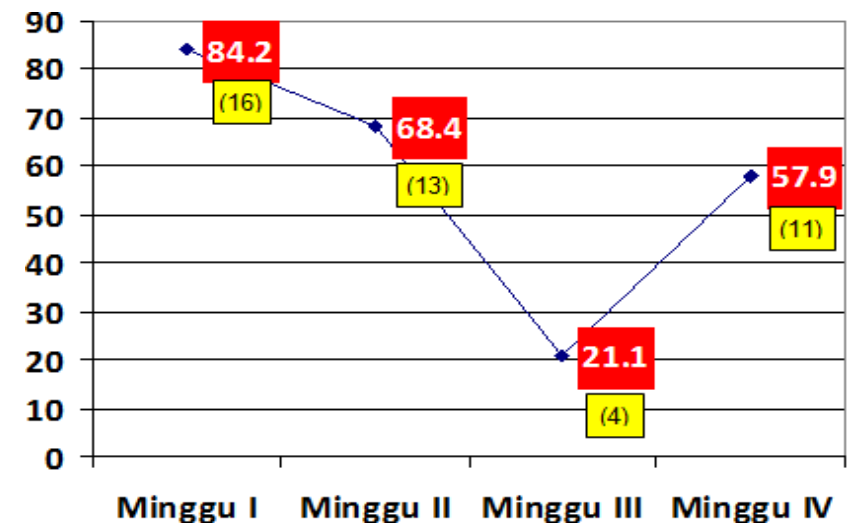

Gambar 6. Distribusi persentase rumah siswa SD Inpres 24 dengan jentik nyamuk positif selama minggu I s.d IV. (Keterangan : angka dalam kotak merah adalah angka persentase, angka dalam kotak kuning adalah angka numerik)

Distribusi tempat-tempat perindukan nyamuk terangkum pada Tabel 4. Tiap siswa yang menemukan jentik nyamuk, hanya menuliskan 1 macam tempat perindukan saja. Dari 94 tempat perindukan yang dilaporkan, ember merupakan tempat perindukan nyamuk terbanyak, diikuti bak mandi dan drum, ban bekas, kaleng bekas, profil, bambu, botol bekas. Ada 12 siswa yang menemukan jentik nyamuk di 2 macam tempat, yaitu got/parit dan kolam, yang sebenarnya bukanlah tempat perindukan nyamuk Aedes. Pada analisis berikutnya, penemuan jentik nyamuk pada tempat perindukan bukan jentik nyamuk Aedes, dihitung sebagai jentik nyamuk negatif. Dari 34 rumah siswa, hasil survei jentik nyamuk terangkum pada Gambar 7 dan Tabel 5. Selama 4 minggu pemantauan tersebut, persentase rumah siswa SD Negeri 22 dengan jentik nyamuk positif berkisar $52.9-70.6 \%$ dengan rerata $60.3 \%$.

Data survei jentik nyamuk berhasil dikumpulkan oleh siswa di kedua SD. Minat siswa SD Negeri 22 lebih tinggi daripada siswa SD Inpres 24 dalam melakukan survei jentik 
nyamuk. Hanya sekitar 30\% siswa SD Inpres 24 dari total yang mengikuti pelatihan yang melakukan survei jentik nyamuk, sedangkan di SD Negeri 22 sekitar 97\%. Perhatian guru pendamping di SD Negeri 22 saat pelatihan tampak lebih besar, bahkan sampai dengan pengumpulan dan pengiriman data survei jentik nyamuk. Ada 2 (2/46; 4.3\%) kesalahan penemuan tempat jentik nyamuk di SD Inpres 24, dan ada 12 kesalahan $(12 / 94 ; 12.8 \%)$ di SD Negeri 22. Kebanyakan siswa sudah melakukan identifikasi jentik nyamuk dengan benar, sedikit di antaranya melakukan kesalahan yaitu mencari jentik nyamuk di genangan air yang kotor (parit/got, kolam dan bak sampah). Dari tempat perindukan yang dilaporkan, tiap kali survei siswa hanya mencatat 1 macam tempat perindukan. Siswa di SD Inpres 24 dan SD Negeri 22 melaporkan 3 tempat perindukan jentik nyamuk terbanyak yaitu bak mandi, drum dan ember, dengan urutan dan persentase yang berbeda. Bak mandi dan ember merupakan tempat air yang digunakan sehari-hari; sedangkan drum ternyata juga banyak dijumpai di lingkungan rumah, mungkin karena daerah kabupaten Sorong juga merupakan penghasil minyak.

Diharapkan, pelatihan survei jentik nyamuk ini selain meningkatkan kemampuan siswa dalam mengidentifikasi jentik nyamuk, juga yang terpenting adalah meningkatkan awareness dalam mengeliminasi tempat perindukan jentik nyamuk. Selama 4 minggu pemantauan jentik nyamuk yang dilakukan siswa, tampak ada penurunan temuan jentik nyamuk pada minggu II. Siswa SD Inpres 24 bahkan melaporkan penurunan temuan jentik nyamuk paling tinggi pada minggu III. Namun demikian, dijumpai lagi peningkatan temuan jentik nyamuk pada minggu berikutnya. Tampaknya, awareness siswa perlu ditingkatkan. Dengan melatih siswa melakukan pemantauan jentik nyamuk, kesadaran untuk berperilaku sehat/ menciptakan lingkungan sehat tidak hanya ditujukan untuk siswa itu sendiri, tapi juga diharapkan siswa tersebut menularkan kemampuan tersebut kepada orang-orang di sekitarnya, termasuk orang tua mereka.

Tabel 4. Urutan terbanyak tempat perindukan jentik nyamuk di lingkungan rumah siswa SD Negeri 22 selama minggu I s.d minggu IV

\begin{tabular}{lc}
\hline \multicolumn{1}{c}{ Tempat perindukan jentik nyamuk } & Jumlah (persenta \\
\hline Ember & $22(23.4)$ \\
Bak mandi & $15(15.9)$ \\
Drum & $15(15.9)$ \\
Ban bekas & $12(12.8)$ \\
Kaleng bekas & $7(7.5)$ \\
Baskom & $5(5.3)$ \\
Profil & $4(4.3)$ \\
Bambu & $1(1.1)$ \\
Botol bekas & $1(1.1)$ \\
Got/parit* & $11(11.7)$ \\
Kolam* & $1(1.1)$ \\
Total & $94(100)$
\end{tabular}

(Keterangan : * bukan tempat perindukan jentik nyamuk Aedes) 
Tabel 5. Keberadaan jentik nyamuk di lingkungan rumah siswa SD Negeri 22 selama minggu I s.d minggu IV

\begin{tabular}{|c|c|c|c|c|c|}
\hline \multicolumn{4}{|c|}{ Keberadaan jentik nyamuk } & \multirow{2}{*}{$\begin{array}{c}\text { Jumlah } \\
\text { (persentase) } \\
\text { rumah }\end{array}$} & \multirow{2}{*}{$\begin{array}{c}\text { Total } \\
\text { persentase } \\
\text { rumah }\end{array}$} \\
\hline Minggu I & Minggu II & Minggu III & Minggu IV & & \\
\hline \multicolumn{6}{|c|}{ Tidak ada perubahan } \\
\hline+ & + & + & + & $5(14.7)$ & 20.6 \\
\hline- & - & - & - & $2(5.9)$ & \\
\hline \multicolumn{6}{|c|}{ Menunjukkan penurunan jentik nyamuk positif } \\
\hline+ & - & - & - & $4(11.8)$ & 17.6 \\
\hline+ & + & - & - & $1(2.9)$ & \\
\hline+ & + & + & - & $1(2.9)$ & \\
\hline \multicolumn{6}{|c|}{ Menunjukkan fluktuasi keberadaan jentik nyamuk } \\
\hline+ & - & + & - & $4(11.8)$ & \\
\hline- & + & + & + & $4(11.8)$ & \\
\hline+ & - & + & + & $4(11.8)$ & \\
\hline+ & + & - & + & $4(11.8)$ & 61.9 \\
\hline+ & - & - & + & $2(5.9)$ & \\
\hline- & + & + & - & $2(5.9)$ & \\
\hline- & + & - & + & $1(2.9)$ & \\
\hline Total & & & & $34(100)$ & 100 \\
\hline
\end{tabular}

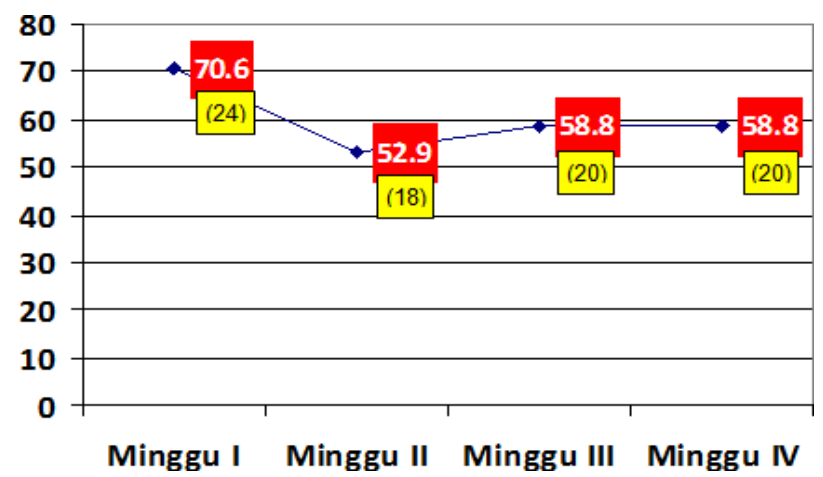

Gambar 7. Distribusi persentase rumah siswa SD Negeri 22 dengan jentik nyamuk positif selama minggu I s.d IV. (Keterangan : angka dalam kotak merah adalah angka persentase, angka dalam kotak kuning adalah angka numerik)

Setelah dilakukan penyuluhan, salah satu siswa didampingi melakukan identifikasi tempat-tempat perindukan jentik nyamuk di lingkungan rumahnya. Siswa tersebut menunjukkan respon dan minat yang baik saat mencari tempat perindukan jentik nyamuk. Respon orang tua siswa tersebut juga baik saat mengikuti si siswa melakukan pemantauan jentik nyamuk, bahkan saat ditemukan jentik nyamuk di ban bekas di lingkungan rumahnya, ibu si siswa meminta tolong suaminya untuk menyimpan ban bekas dengan benar agar tidak ada lagi nyamuk yang bertelur di tempat itu. Hal seperti ini yang diharapkan pada semua siswa yang dilatih.

Pada minggu I pemantauan, sebanyak $84.2 \%$ rumah siswa SD Inpres 24 dan $70.6 \%$ 
rumah siswa SD Negeri 22 dijumpai jentik nyamuk. Selama 4 minggu pemantauan, rumah siswa SD Inpres 24 yang tetap menunjukkan jentik nyamuk positif sebanyak $21.1 \%$ sedangkan di rumah siswa SD Negeri 22 sebanyak 14.7\%. Sekitar 5.9- 10.5\% rumah siswa di kedua SD stabil menunjukkan jentik nyamuk negatif. Sebanyak $17.6 \%$ rumah siswa SD Negeri 22, bahkan sebanyak 31.6\% rumah siswa SD Inpres 24 yang menunjukkan perubahan dari jentik nyamuk positif menjadi negatif pada minggu II, III atau IV. Fluktuasi keberadaan jentik nyamuk (setelah negatif, menjadi posiitif lagi) dijumpai pada $36.9 \%$ di rumah siswa SD Inpres 24 bahkan $61.9 \%$ di rumah siswa SD Negeri 22 (Tabel 3 dan 5). Selama 4 minggu pemantauan tersebut, persentase rumah siswa SD Inpres 24 dengan jentik nyamuk positif berkisar $21.1-84.2 \%$ dengan rerata 57.9\%; sedangkan rumah siswa SD Negeri 22 dengan jentik nyamuk positif berkisar 52.9 - 70.6\% dengan rerata $60.3 \%$. Dibandingkan dengan data dari Puskesmas Mayamuk pada bulan Januari 2017 yang menunjukkan rerata jentik nyamuk positif $41.8 \%$, data jentik nyamuk yang diperoleh siswa SD Inpres 24 dan SD Negeri 22 menunjukkan rerata lebih tinggi $(57.9-60.3 \%)$. Perlu dikonfirmasi data yang diperoleh siswa. Namun demikian, perlu dilakukan penyuluhan lagi untuk menciptakan perilaku eliminasi tempat perindukan jentik nyamuk lebih baik lagi.

\section{Data Kadar $\mathrm{Hb}$}

SD Inpres 24

Pemeriksaan kadar $\mathrm{Hb}$ dilakukan pada 50 siswa, terdiri dari 27 siswa laki-laki dan sisanya (23) siswa perempuan, dengan rentang usia 6-11 tahun (rerata 7.34 tahun). Kadar Hb siswa tersebut berkisar 9.4-14.4, dengan rerata 11.7. Hasil klasifikasi tingkat kadar $\mathrm{Hb}$ dari 50 siswa tersebut, terangkum pada Gambar 8.

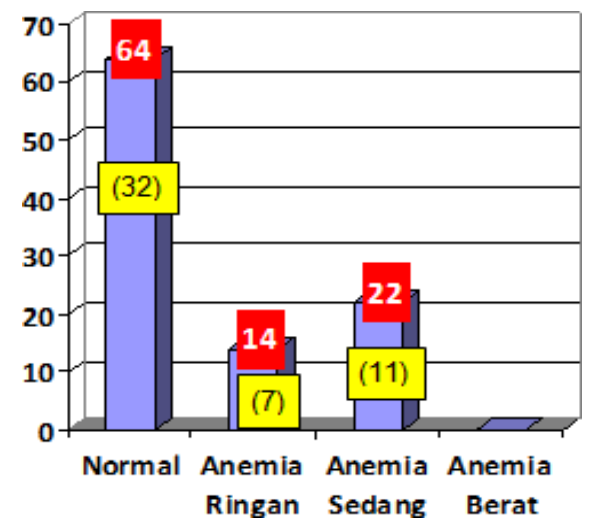

Gambar 8. Distribusi anemia pada siswa SD Inpres 24. (Keterangan : angka dalam kotak merah adalah angka persentase, angka dalam kotak kuning adalah angka numerik)

\section{SD Negeri 22}

Pemeriksaan kadar $\mathrm{Hb}$ dilakukan pada 65 siswa, terdiri dari 34 siswa laki-laki dan sisanya (31) siswa perempuan, dengan rentang usia 6-12 tahun (rerata 7.97 tahun). Kadar Hb siswa tersebut berkisar 8.8 - 18.2, dengan rerata 11.3. Hasil klasifikasi tingkat kadar $\mathrm{Hb}$ dari 65 siswa tersebut, terangkum pada Gambar 9. 


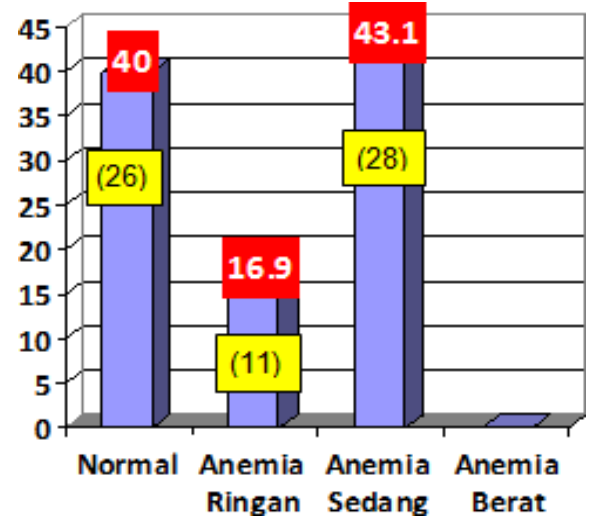

Gambar 9. Distribusi anemia pada siswa SD Negeri 22. (Keterangan : angka dalam kotak merah adalah angka persentase, angka dalam kotak kuning adalah angka numerik)

Sebagian besar (60\%) siswa di SD Negeri 22 menderita anemia, terdiri dari anemia sedang $(43.1 \%)$ diikuti anemia ringan (16.9\%) (Gambar 9). Sedangkan siswa di SD Inpres 24 sebagian besar menunjukkan kadar $\mathrm{Hb}$ normal, diikuti yang menderita anemia sebanyak $38 \%$ (terdiri dari anemia sedang sebanyak $22 \%$ dan anemia ringan 14\%) (Gambar 8). Kondisi ini sangat memprihatinkan. Di daerah endemis malaria, sangat perlu dilakukan pemeriksaan skrining parasit malaria dan kadar $\mathrm{Hb}$ secara rutin, agar kasus yang ditemukan dapat segera ditindaklanjuti (diberi pengobatan definitif dan suportif). Keadaan anemia akan menurunkan kondisi fisik siswa secara umum.

\section{PENUTUP}

\section{Simpulan}

Penyuluhan belum dapat meningkatkan pengetahuan tentang malaria dan dengue pada siswa SD di Sorong. Pelatihan kader pemantau jentik nyamuk pada siswa SD di Sorong dapat meningkatkan ketrampilan dalam memantau jentik nyamuk (vektor DBD), namun upaya untuk melakukan eliminasi tempat perindukan jentik nyamuk perlu ditingkatkan secara terus-menerus. Proporsi anemia pada siswa SD di Sorong sebanyak 38-60\%.

\section{Saran}

Perlu upaya pihak sekolah dan Puskesmas untuk meningkatkan pengetahuan dan ketrampilan siswa dalam berperan serta menanggulangi penyakit malaria dan dengue. Perlu upaya aktif pihak Puskesmas dalam memberikan penyuluhan kesehatan rutin kepada masyarakat. Perlu surveilens kontinyu dari petugas Puskesmas dalam memantau kadar $\mathrm{Hb}$ dan deteksi dini malaria serta upaya pencegahan dan pengobatannya sedini mungkin. Dukungan SDM dan fasilitas laboratorium Puskesmas sangat diharapkan dapat mengatasi masalah kesehatan ini.

\section{DAFTAR PUSTAKA}

Abdussalam, R., Rosaline, N. I., Krimadi, Siregar, R., Lestari, E. D., Salimo, H. (2016). Profil Infeksi Plasmodium, Anemia dan Status Nutrisi pada Malaria Anak di 
RSUD Scholoo Keyen, Kabupaten Sorong Selatan. Sari Pediatri, 17, 446-449.

Badan Pusat Statistik (BPS) Kabupaten Sorong. (2017). Kabupaten Sorong Dalam Angka 2017. Sorong : BPS Kabupaten Sorong (http://www. sorongkab.bps. go.id)

Dinas Kesehatan (Dinkes) Kota Sorong. (2015). Laporan Malaria Bulanan Tahun 2014.

Dinas Kesehatan (Dinkes) Papua. (2017). https://dinkes.papua.go.id/. Diakses pada 20 Februari 2017.

Ditjen PP \& PL Kemenkes RI. (2014). Buku Saku Penatalaksanaan Kasus Malaria. Jakarta : Kementerian Kesehatan RI.

Elyazar, F.R., Iqbal, Hay, I.S., Baird, K.J. (2011). Malaria Distribution, Prevalence, Drug Resistance And Control in Indonesia. Advance Parasitology, 74, 41-175.

Media Papua. (2016).Gerakan Kebas MalariaTerus Disosialisasikan. (http://mediapapua.com/news/read/ind ex/10/3841/gerakan-kebas-malariaterus-disosialisasikan)

Pusat Data dan Surveilans Epidemiologi, Kemenkes RI. 2010. Demam Berdarah Dengue. Buletin Jendela Epimiologi, 2, 1-14.

WHO. (2014). Severe malaria. John Wiley and Sons : Tropical Medicine and International Health, 19.

WHO. (2017). Malaria Media Centre. (http://www.who.int/mediacentre/facts heets/fs094/en/)

Zega, A. 2006. Hubungan Kejadian Malaria dengan Penghasilan, Pendidikan, Perilaku Pengobatan Masyarakat di Kabupaten Kulon Progo. (http://digilib.litbang.depkes.go.id). Diakses pada 21 Maret 2013. 